\title{
Comparison of Clinical and Radiographic Changes after Bryan Disc Arthroplasty versus ACDF: A 60-Month Follow-Up on 120 Patients
}

\author{
Fujiang Cao', Tao Liu' ${ }^{*}$, Yunqiang Xu ${ }^{1}$, Hui Han², Ronghua Dong², Shiqing Feng1\# \\ ${ }^{1}$ Department of Orthopaedic Surgery, General Hospital of Tianjin Medical University, Tianjin, China \\ ${ }^{2}$ Department of Orthopaedic Surgery, Tianjin TEDA Hospital, Tianjin, China \\ Email: "fengsq9@126.com
}

Received 3 January 2015; accepted 25 January 2015; published 28 January 2015

Copyright (C) 2015 by authors and Scientific Research Publishing Inc.

This work is licensed under the Creative Commons Attribution International License (CC BY). http://creativecommons.org/licenses/by/4.0/

(c) (i) Open Access

\begin{abstract}
Background: Artificial cervical disc replacement has become an option for cervical radiculopathy. Previous studies have evaluated the efficacy of this alternative without the scientific rigor of a concurrent control population in oriental patients for long-term follow-up. Objective: Therefore, we asked whether the 1) clinical and 2) radiographic outcomes of Bryan cervical disc prosthesis were better than that of anterior cervical discectomy and fusion (ACDF) at single site, and whether the 3) occurrences of heterotopic ossifications (HOs) were associated to the function loss in the long-term follow-up. Methods: A total of 120 patients with cervical disc disease were randomly assigned to two groups (Bryan or ACDF), and 60-month follow-up is available for all the 120 patients. Clinical outcomes were assessed using Odom's criteria, visual analogue pain scale (VAS) and Neck Disability Index (NDI). Radiographs were measured to determine the radiographic outcomes and occurrences of heterotopic ossifications (HOs). Results: The clinical outcomes are not significantly between the two groups (VAS, $\mathrm{P}=0.7253$; NDI, $\mathrm{P}=\mathbf{0 . 5 5 2 8}$ ). The radiographic outcome of Bryan cervical disc prosthesis is better than that of ACDF group at the index level $(P<0.05) .36(60 \%)$ patients of Bryan group developed heterotopic ossification. But, there is not a significant association between HOs and the loss of movement at the replacement level. Conclusions: The Bryan artificial disc replacement compares favorably to ACDF for the treatment of patients with 1-level cervical disc disease. And the Bryan disc may delay adjacent level degeneration by preserving preoperative kinematics at adjacent levels in oriental patients.
\end{abstract}

\footnotetext{
${ }^{*}$ Co-first author.

\#Corresponding author.
}

How to cite this paper: Cao, F.J., Liu, T., Xu, Y.Q., Han, H., Dong, R.H. and Feng, S.Q. (2015) Comparison of Clinical and Radiographic Changes after Bryan Disc Arthroplasty versus ACDF: A 60-Month Follow-Up on 120 Patients. World Journal of Neuroscience, 5, 40-48. http://dx.doi.org/10.4236/wjns.2015.51005 


\section{Keywords}

\section{Bryan Disc, ACDF, Follow-Up}

\section{Introduction}

In recent years, much effort has been made to investigate the use of the artificial disc systems as an alternative to fusion. It is well-documented that the immediate and short-term results of artificial disc arthroplasty are equivalent to those of ACDF [1] [2]. Disc arthroplasty has the additional advantages of being able to maintain cervical motion and reduce the incidence of adjacent segment degeneration. Several centers [3]-[6] have reported the use of the Bryan disc in the management of adjacent segment degeneration associated with previous fusion surgery and surgery at the cervicothoracic junction, and the short-term outcomes of Bryan disc replacement. However, there are not so much reports about the comparision with ACDF for a long-term follow-up, particularly in oriental patients. The Bryan Cervical Disc prosthesis was available in our hospital since January 2004 and used with great enthusiasm in the hope that it could prevent adjacent segment disease, which was a well known late complication of anterior cervical discectomy and fusion (ACDF). The clinical outcome of cervical arthroplasty in oriental patients is not often seen in English literature.

Therefore, we collected and analyzed the data of the patients who underwent cervical arthroplasty with the Bryan Cervical Disc prosthesis to see whether the 1) clinical and 2) radiographic outcomes of Bryan cervical disc prosthesis were better than that of anterior cervical discectomy and fusion (ACDF) at single site, and whether the 3) occurrences of heterotopic ossifications (HOs) were associated to the function loss in the longterm follow-up.

\section{Patients and Methods}

From March 2004, we started an observational clinical study with the aim of evaluating the safety and efficacy of the Bryan disc arthroplasty for the treatment of cervical spondylosis.

The study consisted of 120 patients with spondylotic myelopathy or cervical radiculopathy. All the patients signed the informed consent and an assurance of free X-ray examinations when they come back for the postoperative follow-up visits to our hospital. The patients were randomized into 2 groups: 1) 60 patients underwent discectomy and implantation of the Bryan disc. The least follow-up period was 60 months. The study group consisted of 35 men and 25 women. The mean age was 41.0 years (27 to $51 \mathrm{y}$ ). The levels of surgery included C3/4 (6 patient), C4/5 (15 patients), C5/6 (33 patients), and C6/7 (6 patients) (Table 1); 2) 60 patients underwent anterior cervical discectomy with fusion with autologous bone graft and all gained at least 60 months follow-up. The study group consisted of 31 men and 29 women. The mean age was 44.0 years (27 to 62 y). The levels of surgery included C3/4 (5 patients), C4/5 (16 patients), C5/6 (30 patients), and C6/7 (9 patients) (Table 2).

\subsection{Clinical Analysis}

The routine follow-up examination included general and neurologic evaluations. Clinical outcomes were

Table 1. Patient's demographics (Bryan and ACDF artificial disc).

\begin{tabular}{|c|c|c|}
\hline & Bryan & ACDF \\
\hline Number of patients & 60 & 60 \\
\hline Mean age (y) & $41(27-51)$ & $44(27-62)$ \\
\hline Gender (male:female) & $35: 25$ & $31: 29$ \\
\hline Radiculopathy & 52 & 55 \\
\hline Myelopathy & 8 & 5 \\
\hline Level implanted & $\begin{array}{l}C 3 / 4(n=6) ; C 4 / 5(n=15) ; \\
C 5 / 6(n=33) ; C 6 / 7(n=6)\end{array}$ & $\begin{array}{l}C 3 / 4(n=5) ; C 4 / 5(n=16) ; \\
C 5 / 6(n=30) ; C 6 / 7(n=9)\end{array}$ \\
\hline
\end{tabular}


assessed by an independent third party (unaware of relevant patient details) using the Neck Disability Index (NDI) [7] and Odom's scale. The Odom's scale is the most commonly used scale and is relatively simple. We evaluated the patients' pain relief using VAS pain score.

\subsection{Radiologic Analysis}

Radiologic examinations are performed preoperatively and at each follow-up visit. Each year, a radiologist evaluates whether there is fusion on $\mathrm{CT}$ and plain X-ray. The radiographic results were assessed by taking AP, lateral, bending, flexion, and extension radiographs of cervical spine in the postoperation 1, 12, 24, 36, 48, 60 months follow-up to find out the range of motion (ROM) and device position. To analyze movement at the treated level, we measured the functional spinal unit (FSU) angle, Cobb angles of the cervical spine (from the lower end plate of C2 to the inferior end plate of C7), and adjacent segment angles (Figure 1). All parameters were measured by Quantitative Motion Analysis software (QMA; Medical Metrics Inc., Houston, TX, USA). In this study, radiological signs of degenerative changes at the upper and lower functional adjacent levels have been assessed using the McAfee classification [4] in the 120 patients.

\section{Table 2. McAfee classification.}

\begin{tabular}{cc}
\hline Grade & Description \\
Grade 0 & Segments without any new HO formation after prosthesis implantation. \\
Grade I & Segments with new HO formation not reaching the intervertebral space. \\
Grade II & HO reaches the intervertebral space but segmental movement is not limited. \\
Grade III & Important bridging ossifications with limited, but possible movement. \\
Grade IV & Segmental fusion. \\
\hline
\end{tabular}

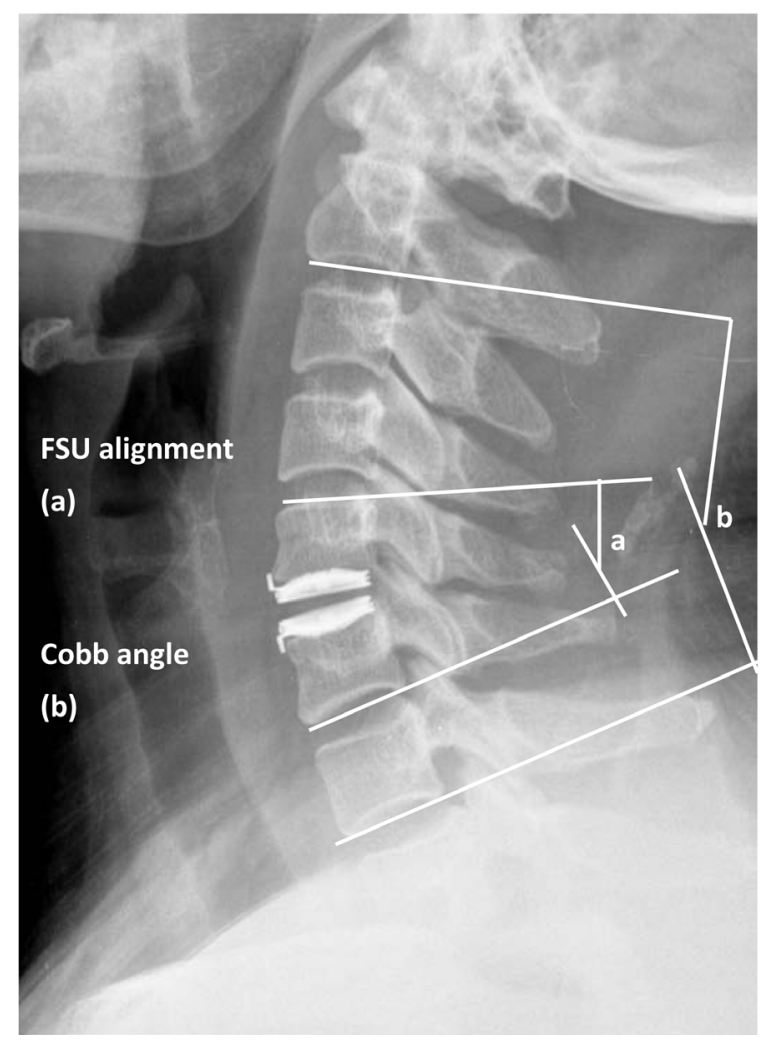

Figure 1. The FSU (a) and overall cervical (C2-7) alignment; (b) were measured by Cobb’s method. 


\subsection{Statistical Analysis}

A paired t test was used to assess the statistical significance of postoperative score change from the preoperative in NDI and VAS. It was also used for analysis of motion parameters at the treated level when change from preoperative angulation was recorded. SPSS for Windows (version 17.0.1; SPSS Inc., Chicago, IL, USA) was used for the analysis. A P $<0.05$ was customarily considered significant.

\section{Results}

\subsection{Clinical Outcomes}

The mean NDI before surgery was not statistically different between groups: 45.5 (Bryan) and 46.2 (control). one-month postoperative NDI is 14.2 (Bryan) and 15.4 (control) $(\mathrm{P}=0.013$ ). At 1-year follow-up, NDI for the Bryan group is 10.2 and the control group is $15.4(\mathrm{P}=0.005)$. At 3-year: 8.4 (Bryan) and 10.2 (control) $(\mathrm{P}=$ 0.005). The final follow-up: 7.2 (Bryan) and 8.8 (control) $(\mathrm{P}=0.005)$ (Figure 2). The mean arm pain VAS before surgery was 75 (Bryan) and 74 (control). At 1-month follow-up, Bryan arm pain VAS was 18 and control $22(\mathrm{P}=0.032)$. At 1-year follow-up, the average arm pain VAS for the Bryan group was 17 and control $19(\mathrm{P}=$ 0.036). At 3-year follow-up, the average arm pain VAS for the Bryan group was 14 and control $18(\mathrm{P}=0.035)$. The final follow-up: 12 (Bryan) and 17 (control) $(\mathrm{P}=0.031)$ (Figure 3). The mean neck pain VAS before surgery was 75 (Bryan) and 78 (control). One-month follow-up scores were 23 (Bryan) and 36 (control) $(\mathrm{P}=0.05)$. At 1 year: 27 (Bryan) and 30 (control) $(\mathrm{P}=0.037)$. At 3 years: 20 (Bryan) and 27 (control) $(\mathrm{P}=0.013)$. The final follow-up: 22 (Bryan) and 26 (control) $(\mathrm{P}=0.033$ ) (Figure 4). When surgical outcome was measured using Odom criteria, as assessed by the surgeon who had performed the operation, it was observed that most of the patients had a satisfactory outcome (excellent, good or fair) and no patient was allocated to "poor" (Table 3).

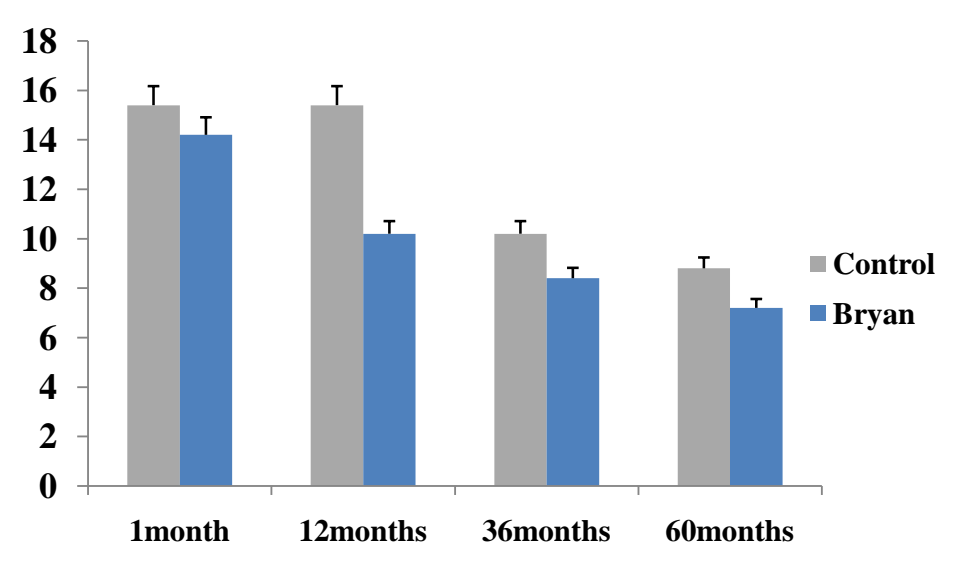

Figure 2. Neck dysfunction score indicators (Neck Disability Index, NDI).

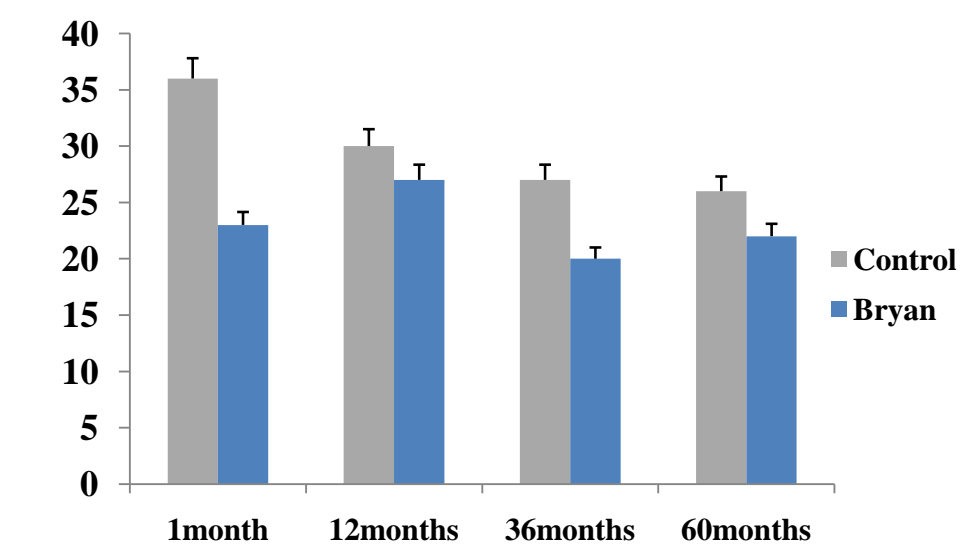

Figure 3. Neck visual VAS score. 


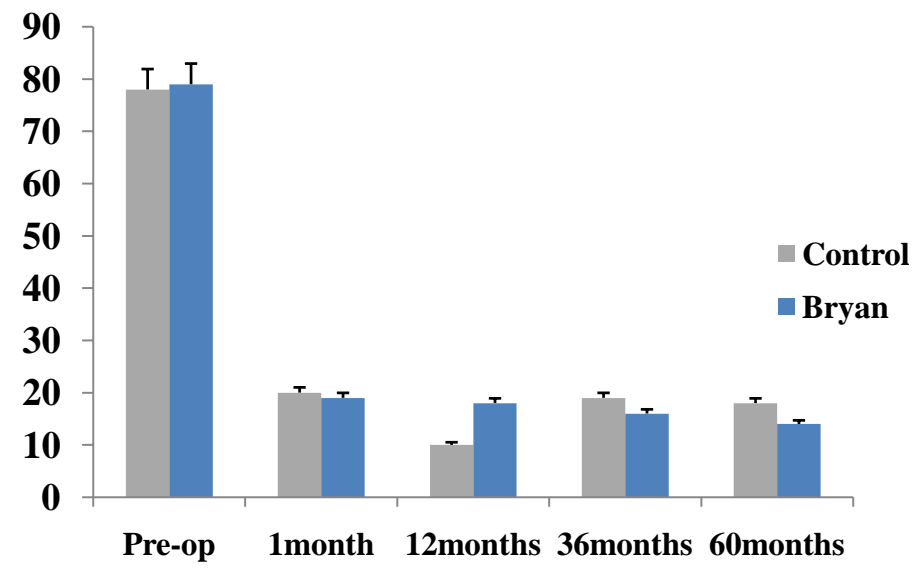

Figure 4. Upper limb pain visual score.

Table 3. Clinical results of Odom's criteria.

\begin{tabular}{cccccc}
\hline & $\mathrm{N}$ & Excellent (\%) & Good (\%) & Fair (\%) & Poor (\%) \\
\hline Bryan & 60 & $37(61.7)$ & $18(30.0)$ & $5(8.3)$ & $0(0)$ \\
ACDF & 60 & $29(60.0)$ & $23(33.3)$ & $8(6.7)$ & $0(0)$ \\
\hline
\end{tabular}

\subsection{Radiological Outcomes}

Sagittal ROM at the operated level was greater in patients with Bryan disc (7.25 degrees; SD, 1.5 degrees) than patients with ACDF ( 0.80 degrees; SD, 0.84 degrees) at the time of the late follow-up evaluation $(\mathrm{P}<0.001)$. There were no other statistically significant differences in kinematic parameters between the two groups at the two immediately adjacent rostral spinal levels. Late follow-up kinematic data at adjacent spinal levels is presented in Figure 4. A nonpaired $\mathrm{t}$ test demonstrated significantly $(\mathrm{P}<0.05)$ increased translation at the surgical level in Bryan (7.2\%; SD, 4.5\%) in comparison to all patients before surgery (4.7\%; SD, 3.5\%), whereas ROM did not differ significantly $(\mathrm{P}>0.5$ ) between all patients preoperatively (6.4 degrees; SD, 3.7 degrees).

One month after surgery, cervical lordosis fell from 28.55 to 27.54 in the Bryan group and from 26.27 to 24.69 in the ACDF group. In the Bryan group, lordosis increased during the immediate postoperative period and then decreased to preoperative levels. In the ACDF group, however, lordosis decreased gradually, and could not return to preoperative levels (Figure 5). Segmental ROM of the treated level changed from 6.50 to 7.25 in the Bryan group and fell from 7.00 to 0.82 in the ACDF group. Although segmental lordosis in the Bryan group maintained more than preoperative levels, the lordosis became a little more kyphotic than before surgery in the ACDF group (Figure 6). Upper segmental ROM of the Bryan group decreased one month after the surgery, from 12.82 to 8.70 , whereas upper segmental ROM of the fusion group increased, from 11.8 to $8.36(\mathrm{P}>0.05)$ (Figure 2(c)). Although upper segmental ROM increased postoperatively in both groups, the increase was higher in the Bryan group than in the ACDF group (from 8.7 to 11.40 vs. from 8.30 to 10.2, P > 0.05) (Figure 7). Although lower segmental ROM of the both groups decreased one month after the surgery, increased postoperatively gradually, the increase was still higher in the Bryan group than in the ACDF group (from 7.70 to 7.80 vs. from 6.30 to $6.70, \mathrm{P}>0.05$ ) (Figure 8).

At 12-month follow-up, in the Bryan group, HO of Grade 0-II was present in 54 (91\%) of treated levels and significant HO (Grade III) in another 6 (9\%). Segmental fusion (Grade IV) was not observed. At 3-year followup, HOs of Grade 0-II was present in 51 (85\%) of treated levels, important HO (Grade III) in 15 (15\%). At 5year follow-up, HO of Grade 0-II was present in 45 (75\%), important HO (Grade III) in 12 (20\%) and segmental ankylosis (Grade IV) in 3 (5\%) treated levels. At the final follow-up, the HO in the ACDF group is $100 \%$.

\section{Discussion}

The long-term clinical benefit of maintaining motion is postulated to be the delay or avoidance of adjacent level 


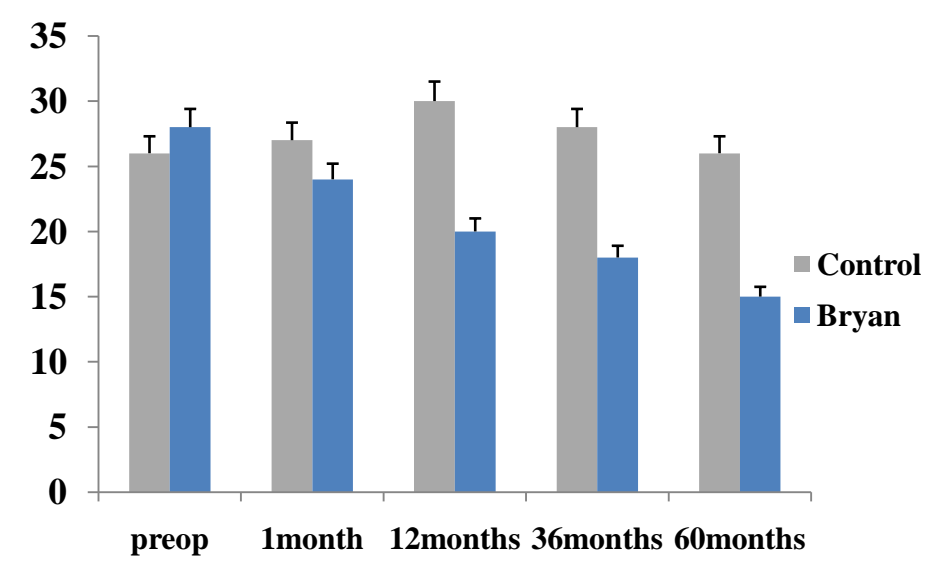

Figure 5. C2-7 Cobb angle.

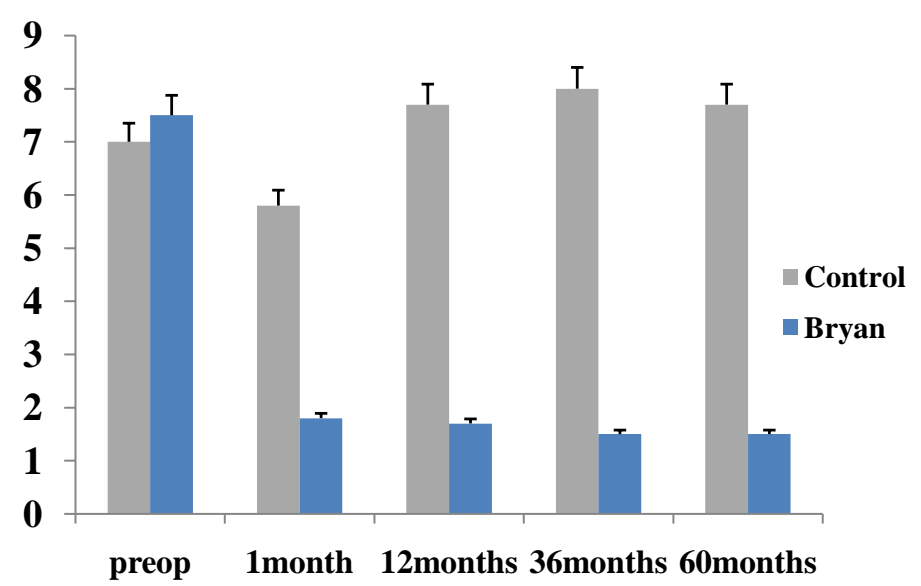

Figure 6. ROM of the treated level.

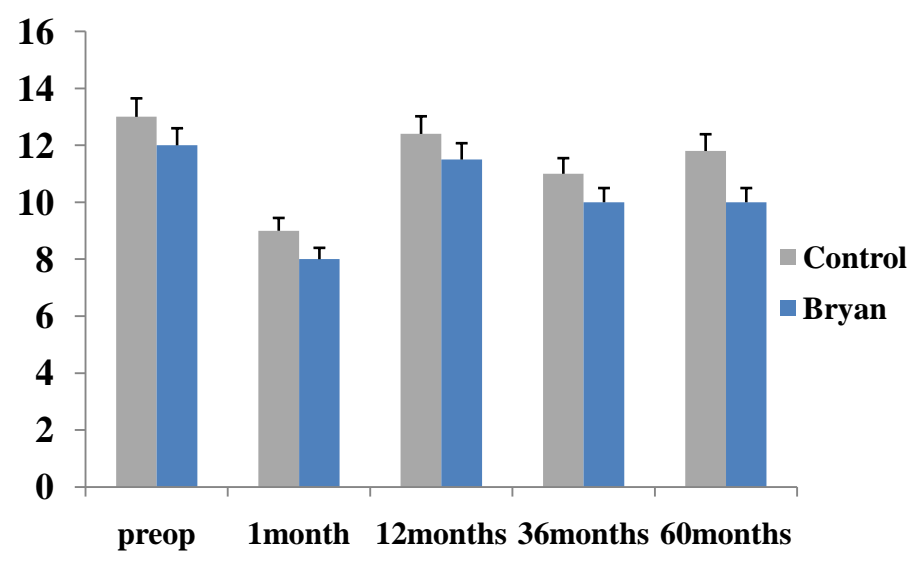

Figure 7. FSU adjacent segmental ROM of upper segment.

degeneration [9]-[12]. Disc replacement aims to preserve the normal kinematics in the spine. The Bryan disc is one of several arthroplasty systems currently being investigated for use in the cervical spine. While each of these devices has early outcome data, long-term studies of comparison Bryan disc arthroplasty with ACDF, also assessing adjacent segment degeneration are still pending, particularly in oriental patients. Therefore, we asked whether the 1) clinical and 2) radiographic outcomes of Bryan cervical disc prosthesis were better than that of 
anterior cervical discectomy and fusion (ACDF) at single site, and whether the 3) occurrences of heterotopic ossifications (HOs) were associated to the function loss in the long-term follow-up.

In our study, we have got good clinical results. All of the patients were satisfied with the surgical results by Odom's criteria, and showed significant improvement by VAS and NDI score $(\mathrm{P}<0.05)$ from pre-op to final follow-up. The Odom's criteria, VAS and NDI score were not determined to be significantly different between Bryan and ACDF groups at adjacent segments.

Heller et al. [12] declared that at 48 months there had been no degradation of functional outcomes from 24 to 48 months for NDI, VAS of neck and arm (Table 4). One of the potential criticisms about artificial discs is that in the absence of fusion there may be further pain. Our analysis of VAS and NDI shows that this has not been a problem in our patients. Kim et al. [13] and Rick et al. [14] showed decreased VAS and NDI scores on last follow up, but they announced that it was due to the initial surgical decompression and removal of pathologically herniated discs. Our study found similar results. We believe that it may due to the aging and degeneration at adjacent segments.

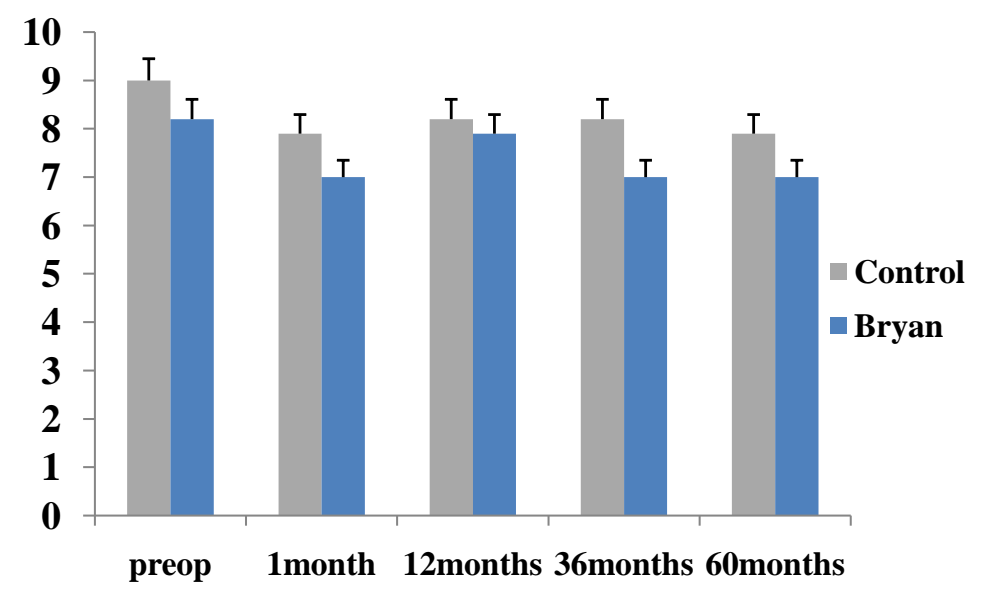

Figure 8. FSU adjacent segmental ROM of lower level.

Table 4. Published data on the follow-up of Bryan disc arthoplasty.

\begin{tabular}{|c|c|c|c|c|c|c|c|c|c|c|}
\hline \multirow[t]{2}{*}{ Study } & \multirow{2}{*}{$\begin{array}{l}\text { Mean } \\
\text { follow-up } \\
\text { (months) }\end{array}$} & \multirow{2}{*}{$\begin{array}{l}\text { Number of } \\
\text { patients } \\
\text { (Bryan vs } \\
\text { ACDF) }\end{array}$} & \multirow{2}{*}{$\begin{array}{l}\text { Mean age } \\
\text { (years) } \\
\text { (Bryan vs } \\
\text { ACDF) }\end{array}$} & \multicolumn{3}{|c|}{$\begin{array}{l}\text { Clinical outcomes improvement at } \\
\text { final follow-up (\%) } \\
\text { (improvement or score) }\end{array}$} & \multicolumn{3}{|c|}{$\begin{array}{l}\text { Radiographic outcomes } \\
\text { at final follow-up } \\
\text { (Bryan vs ACDF) }\end{array}$} & \multirow{2}{*}{$\begin{array}{l}\text { HOs (\%) } \\
\text { (Bryan vs } \\
\text { ACDF) }\end{array}$} \\
\hline & & & & NDI & Neck VAS & Arm VAS & Mean ROM & $\begin{array}{c}\text { Upper } \\
\text { adjcent }\end{array}$ & $\begin{array}{l}\text { Lower } \\
\text { adjcent }\end{array}$ & \\
\hline $\begin{array}{l}\text { Seok Woo } \\
\text { Kim } \\
\text { et al. [13] }\end{array}$ & $\begin{array}{l}19 \text { vs } 20 \\
\text { (Bryan) vs } \\
\text { (ACDF) }\end{array}$ & 51 vs 54 & $\begin{array}{c}43.85 \text { vs } \\
46.44\end{array}$ & 7.2 vs 7.6 & $38 v$ & s 37 & 12.1 vs 2.3 & $\begin{array}{c}9.5 \mathrm{vs} \\
10.2\end{array}$ & $\begin{array}{c}9.2 \mathrm{vs} \\
10.8\end{array}$ & $\begin{array}{c}12.82 \text { vs } \\
23.07 \\
\text { (Grade } 0)\end{array}$ \\
\hline $\begin{array}{l}\text { Ben J. } \\
\text { Garrido } \\
\text { et al. }[8]\end{array}$ & 48 & $\begin{array}{c}47 \\
\text { (21 vs 26) }\end{array}$ & $\begin{array}{c}40.0 \text { vs } \\
43.3\end{array}$ & $\begin{array}{c}80 \% \text { vs } \\
69 \%\end{array}$ & $\begin{array}{c}82 \% \text { vs } \\
67 \%\end{array}$ & $\begin{array}{c}86 \% \text { vs } \\
73 \%\end{array}$ & $\begin{array}{c}\text { Not } \\
\text { reported }\end{array}$ & $\begin{array}{c}\text { Not } \\
\text { reported }\end{array}$ & $\begin{array}{c}\text { Not } \\
\text { reported }\end{array}$ & $\begin{array}{c}\text { Not } \\
\text { reported }\end{array}$ \\
\hline $\begin{array}{l}\text { Clarence } \\
\text { Leung } \\
\text { et al. [7] }\end{array}$ & 12 & 90 (Bryan) & 45 & $\begin{array}{c}\text { Not } \\
\text { reported }\end{array}$ & $\begin{array}{c}\text { Not } \\
\text { reported }\end{array}$ & $\begin{array}{l}\text { Not } \\
\text { reported }\end{array}$ & $\begin{array}{l}\text { Not } \\
\text { reported }\end{array}$ & $\begin{array}{c}\text { Not } \\
\text { reported }\end{array}$ & $\begin{array}{l}\text { Not } \\
\text { reported }\end{array}$ & $\begin{array}{c}6.7 \\
(>\text { Grade 3) }\end{array}$ \\
\hline $\begin{array}{l}\text { Shik Shim } \\
\text { et al. [6] }\end{array}$ & 6 & 61 (Bryan) & 45.6 & $22.9 \%$ & over $50 \%$ & over $50 \%$ & $\begin{array}{l}6.7 \text { (preop): } \\
8.5 \text { (postop) }\end{array}$ & $\begin{array}{c}\text { Not } \\
\text { reported }\end{array}$ & $\begin{array}{c}\text { Not } \\
\text { reported }\end{array}$ & $\begin{array}{c}\text { Not } \\
\text { reported }\end{array}$ \\
\hline $\begin{array}{l}\text { Powell JW } \\
\text { et al. [10] }\end{array}$ & 24 & $\begin{array}{c}48 \\
\text { (22 vs 26) }\end{array}$ & $\begin{array}{c}40.0 \text { vs } \\
43.3\end{array}$ & $\begin{array}{l}\text { Not } \\
\text { reported }\end{array}$ & $\begin{array}{l}\text { Not } \\
\text { reported }\end{array}$ & $\begin{array}{l}\text { Not } \\
\text { reported }\end{array}$ & $\begin{array}{c}8.4 \text { (Bryan): } \\
0.92 \text { (ACDF) }\end{array}$ & $\mathrm{P}>0.4$ & $\mathrm{P}>0.3$ & 11 vs 8 \\
\hline $\begin{array}{l}\text { Rick C. } \\
\text { Sasso } \\
\text { et al. }[14]\end{array}$ & 24 & $\begin{array}{c}463 \\
\text { (221 vs 242) }\end{array}$ & $\begin{array}{c}44.4 \text { vs } \\
44.7\end{array}$ & $\begin{array}{c}\text { Not } \\
\text { reported }\end{array}$ & $\begin{array}{c}\text { Not } \\
\text { reported }\end{array}$ & $\begin{array}{l}\text { Not } \\
\text { reported }\end{array}$ & $\begin{array}{l}7.95 \text { (Bryan): } \\
0.87 \text { (ACDF) }\end{array}$ & $\begin{array}{c}9.1 \\
\text { (Bryan) }\end{array}$ & $\begin{array}{c}6.58 \\
\text { (Bryan) }\end{array}$ & 94.4 (ACDF) \\
\hline $\begin{array}{c}\text { Current } \\
\text { study }\end{array}$ & At least 60 & $\begin{array}{c}120 \\
\text { (60 vs } 60)\end{array}$ & $\begin{array}{c}41.0 \mathrm{vs} \\
44.0\end{array}$ & 7.2 vs 8.8 & 22 vs 26 & 12 vs 17 & 7.25 vs 0.80 & $\begin{array}{c}11.40 \text { vs } \\
10.2\end{array}$ & $\begin{array}{c}7.80 \mathrm{vs} \\
6.70\end{array}$ & $\begin{array}{c}15 \text { vs } 100 \\
\text { (> Grade } 3)\end{array}$ \\
\hline
\end{tabular}


Heterotopic ossification (HO) is a well-known complication after joint replacements which may be responsible for the loss of cervical funtion. Cervical total disc replacements have been performed and investigated widely in recent years, but the significance and incidence of $\mathrm{HO}$ associated with cervical total disc replacement are still pending at present time. However, in our study, we found that $15 \%$ of our patients have developed at least Grade III HOs. We thought that it was due to the Chinese people's physical characteristics. We also found that there was an association between heterotopic ossification and the loss of movement at the level of cervical disc replacement. This may be the reason why there is a degradation of range of motion.

At 60-month follow-up, our study showed that the Bryan disc maintained mobility at the level of the prosthesis, comparable with the ACDF. It is therefore postulated that the Bryan disc decreases risk for degenerative translational motion. Although there is still a theoretical advantage that cervical arthroplasty has a potential to prevent accelerated degeneration of adjacent. However, we feel that this outcome study in Chinese patients suggests that the Bryan Cervical Disc prosthesis has some problems yet to be solved. It would be wise to apply this new technology more carefully to a more specifically selected patient.

\section{Acknowledgements}

This work was funded by National Natural Science Foundation for Young Scholars of China (Grant No 81101362 and 81401784) and Key Project of National Natural Science Foundation of China (81330042). We thank the support from the General Hospital of Tianjin Medical University and Tianjin TEDA Hospital.

\section{Conflict of Interest}

The authors declare no conflict of interest.

\section{References}

[1] Grob, D., Porchet, F., Kleinstück, F.S., Lattig, F. and Jeszenszky, D. (2010) A Comparison of Outcomes of Cervical Disc Arthroplasty and Fusion in Everyday Clinical Practice: Surgical and Methodological Aspects. European Spine Journal, 19, 297-306. http://dx.doi.org/10.1007/s00586-009-1194-3

[2] Garrido, B.J., Taha, T.A. and Sasso, R.C. (2010) Clinical Outcomes of Bryan Cervical Disc Arthroplasty-A Prospective, Randomized, Controlled, Single Site Trial with 48-Month Follow-Up. Journal of Spinal Disorders Techniques, 23, 367-371. http://dx.doi.org/10.1097/BSD.0b013e3181bb8568

[3] Vernon, H. and Mior, S. (1991) The Neck Disability Index: A Study of Reliability and Validity. Journal of Manipulative and Physiological Therapeutics, 14, 409-415.

[4] McAfee, P.C., Cunningham, B.W., Devine, J., Williams, E., Yu-Yahiro, J., et al. (2003) Classification of Heterotopic Ossification (HO) in Artificial Disk Replacement. Journal of Spinal Disorders Techniques, 16, 384-389. http://dx.doi.org/10.1097/00024720-200308000-00010

[5] Ahn, P.G., Kim, K.N., Moon, S.W. and Kim, K.S. (2009) Changes in Cervical Range of Motion and Sagittal Alignment in Early and Late Phases after Total Disc Replacement: Radiographic Follow-Up Exceeding 2 Years. Journal of Neurosurgery: Spine, 11, 688-695. http://dx.doi.org/10.3171/2009.7.SPINE0946

[6] Shim, C.S., Lee, S.H., Park, H.J., Kang, H.S. and Hwang, J.H. (2006) Early Clinical and Radiologic Outcomes of Cervical Arthroplasty with Bryan Cervical Disc Prosthesis. Journal of Spinal Disorders Techniques, 19, 465-470. http://dx.doi.org/10.1097/01.bsd.0000211235.76093.6b

[7] Leung, C., Casey, A.T., Goffin, J., Kehr, P. and Liebig, K. (2005) Clinical Significance of Heterotopic Ossification in Cervical Disc Replacement: A Prospective Multicenter Clinical Trial. Neurosurgery, 57, 759-763. http://dx.doi.org/10.1227/01.NEU.0000175856.31210.58

[8] Garrido, B.J., Taha, T.A. and Sasso, R.C. (2010) Clinical Outcomes of Bryan Cervical Disc Arthroplasty a Prospective, Randomized, Controlled, Single Site Trial with 48-Month Follow-Up. Journal of Spinal Disorders Techniques, 23, 367-371. http://dx.doi.org/10.1097/BSD.0b013e3181bb8568

[9] Singh, K., Phillips, F.M., Park, D.K., Pelton, M.A., An, H.S. and Goldberg, E.J. (2012) Factors Affecting Reoperations after Anterior Cervical Discectomy and Fusion within and outside of a Federal Drug Administration Investigational Device Exemption Cervical Disc Replacement Trial. Spine Journal, 12, 372-378. http://dx.doi.org/10.1016/j.spinee.2012.02.005

[10] Powell, J.W., Sasso, R.C., Metcalf, N.H., Anderson, P.A. and Hipp, J.A. (2010) Quality of Spinal Motion with Cervical Disk Arthroplasty Computer-Aided Radiographic Analysis. Journal of Spinal Disorders Techniques, 23, 89-95. http://dx.doi.org/10.1097/BSD.0b013e3181991413 
[11] Kang, K.C., Lee, C.S., Han, J.H. and Chung, S.S. (2010) The Factors That Influence the Postoperative Segmental Range of Motion after Cervical Artificial Disc Replacement. The Spine Journal, 10, 689-696. http://dx.doi.org/10.1016/j.spinee.2010.04.016

[12] Heller, J.G., Sasso, R.C., Papadopoulos, S.M., Anderson, P.A. and Fessler, R.G. (2009) Comparison of BRYAN Cervical Disc Arthroplasty with Anterior Cervical Decompression and Fusion: Clinical and Radiographic Results of a Randomized, Controlled, Clinical Trial. Spine, 34, 101-107. http://dx.doi.org/10.1097/BRS.0b013e31818ee263

[13] Kim, S.W., Limson, M.A., Kim, S.B., Arbatin, J.J. and Chang, K.Y. (2009) Comparison of Radiographic Changes after ACDF versus Bryan Disc Arthroplasty in Single and Bi-Level Cases. European Spine Journal, 18, 218-231. http://dx.doi.org/10.1007/s00586-008-0854-z

[14] Sasso, R.C., Best, N.M., Metcalf, N.H. and Anderson, P.A. (2008) Motion Analysis of Bryan Cervical Disc Arthroplasty versus Anterior Discectomy and Fusion: Results from a Prospective, Randomized, Multicenter, Clinical Trial. Journal of Spinal Disorders Techniques, 21, 393-399. http://dx.doi.org/10.1097/BSD.0b013e318150d121 
Scientific Research Publishing (SCIRP) is one of the largest Open Access journal publishers. It is currently publishing more than 200 open access, online, peer-reviewed journals covering a wide range of academic disciplines. SCIRP serves the worldwide academic communities and contributes to the progress and application of science with its publication.

Other selected journals from SCIRP are listed as below. Submit your manuscript to us via either submit@scirp.org or Online Submission Portal.
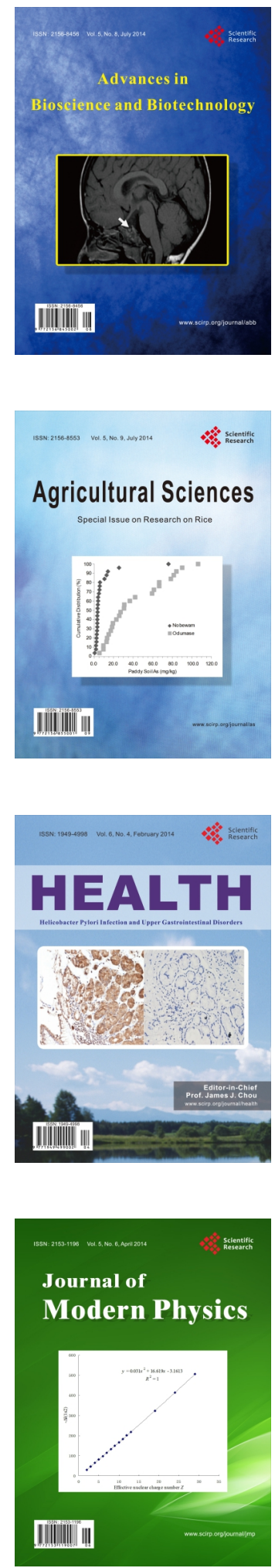
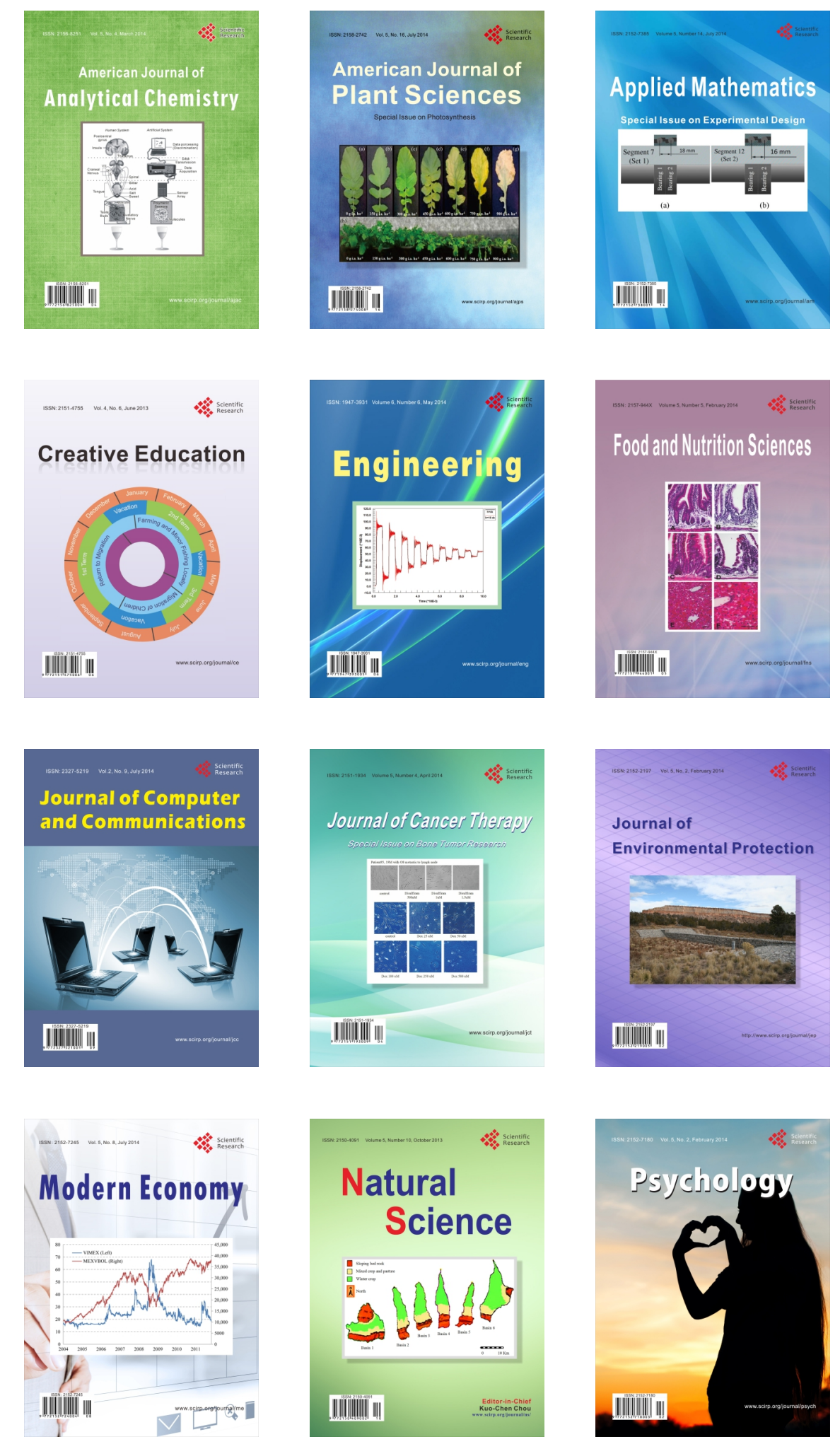